\title{
Mandard Grading System
}

National Cancer Institute

\section{Source}

National Cancer Institute. Mandard Grading System. NCI Thesaurus. Code C140889.

A tumor regression grading (TRG) system commonly used for upper gastrointestinal carcinomas. 